Jurnal DIALOGIKA Manajemen dan Administrasi

Homepage: https://ejurnal.unma.ac.id/index.php/dialogika

Vol. 3 No. 1, Februari 2022, halaman: 10 20

E-ISSN: 2720-9865, P-ISSN: 2716-3563

DOI : https://doi.org/10.31949/dialogika.v3i1.2112

\title{
PENGARUH BUDAYA ORGANISASI DAN MOTIVASI KERJA TERHADAP KINERJA PEGAWAI
}

(Studi pada Dinas Pemberdayaan Masyarakat dan Desa di Kabupaten Majalengka)

\author{
Vina Monica Triany ${ }^{1 *}$, Lalan Soeherlan $S^{2}$, Aceng Jarkasih ${ }^{3}$ \\ (1)Mahasiswa Pascasarjana Ilmu Administrasi, Universitas Majalengka, Jawa Barat, Indonesia \\ (2)(3)Dosen Pascasarjana Ilmu Administrasi, Universitas Majalengka, Jawa Barat, Indonesia \\ e-mail korespondensi: aqueena.sugiarto@gmail.com
}

Disubmit November 2021 , diterima Januari 2022, diterbitkan Februari 2022

Submitted November 2021, Accepted January 2022, Published February 2022

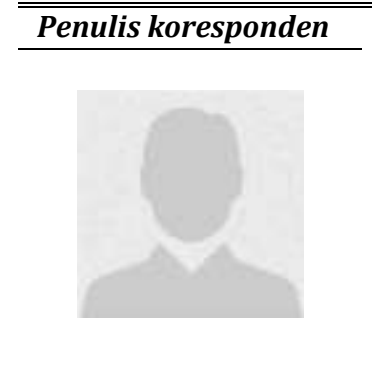

Jurnal DIALOGIKA diterbitkan oleh Program Pascasarjana Administrasi Publik Universitas Majalengka \begin{abstract}
This research aims to analyze organizational culture factors and work motivations their influence on employee performance. The study used quantitative methods by testing hypotheses about the influence of organizational culture and work motivation on employee performance simultaneously and partially. The sample in this study was all 32 active employees using a stratification system based on groups and positions. The results proved that organizational culture and work motivation positively influence employee performance both simultaneously and partially.
\end{abstract}

Keywords: Organizational Culture; Work Motivation; Employee Performance.

Abstrak
Penelitian ini bertujuan untuk menganalisis faktor budaya organisasi dan motivasi
kerja pengaruhnya terhadap kinerja pegawai. Penelitian ini menggunakan metode
kuantitatif dengan menguji hipotesis tentang pengaruh budaya organisasi dan
motivasi kerja terhadap kinerja pegawai baik secara simultan maupun parsial. Sampel
pada penelitian ini adalah seluruh pegawai aktif yang berjumlah sebanyak 32 dengan
memakai sistem stratifikasi berdasarkan golongan dan jabatan. Hasil penelitian
membuktikan bahwa budaya organisasi dan motivasi kerja memiliki pengaruh positif
terhadap kinerja pegawai baik secara simultan maupun parsial.

Kata kunci: Budaya Organisasi, Motivasi Kerja, Kinerja Pegawai.

\section{PENDAHULUAN}

Organisasi merupakan sistem dan kegiatan manusia yang bekerja secara bersama. Sejalan dengan itu, organisasi dikatakan sebagai suatu koordinasi rasional kegiatan sejumlah orang untuk mencapai beberapa tujuan umum melalui pembagian pekerjaan dan fungsi beserta tanggung jawab masing-masing. Organisasi mempunyai tujuan agar dapat memenuhi kebutuhan hidupnya. Oleh sebab itu, organisasi mengharapkan para pegawai dapat berprestasi dan mampu menciptakan situasi dan kondisi yang kondusif, sehingga pegawai tidak akan mengalami kejenuhan, kebosanan, dan malas bekerja yang mengakibatkan penurunan kinerja. "Kinerja karyawan yang menurun akan mengakibatkan kerugian pada organisasi (Listianto dan Setiaji, 2012:2)". Oleh sebab itu, perlu dibentuk adanya kebiasaan atau tata tertib yang akan memberikan suatu budaya organisasi.

Dalam situs psikologizone.com menerangkan bahwa budaya organisasi dapat mempengaruhi cara orang dalam berperilaku dan harus menjadi patokan dalam setiap program pengembangan organisasi dan kebijakan yang diambil. Hal ini terkait dengan bagaimana budaya itu 
mempengaruhi organisasi dan bagaimana suatu budaya itu dapat dikelola oleh organisasi. Situs tersebut juga menerangkan bahwa budaya organisasi sendiri memiliki pengertian adalah budaya organisasi atau budaya perusahaan adalah nilai, norma, keyakinan, sikap dan asumsi yang merupakan bentuk bagaimana orang-orang dalam organisasi berperilaku dan melakukan sesuatu hal yang bisa dilakukan. Nilai adalah apa yang diyakini bagi orangorang dalam berperilaku dalam organisasi. Norma adalah aturan yang tidak tertulis dalam mengatur perilaku seseorang.

Budaya organisasi akan mempengaruhi cara pekerjaan yang dilakukan dan cara pegawai berperilaku serta cara pandang yang sama dalam melakukan aktivitas pekerjaan. Budaya organisasi akan berdampak pada efisiensi dan efektivitas organisasi. Budaya organisasi dapat membantu kinerja pegawai, karena menciptakan tingkat motivasi yang besar bagi pegawai untuk memberikan kemampuan terbaiknya dalam memanfaatkan kesempatan yang diberikan oleh organisasinya. Nilai-nilai yang dianut bersama membuat pegawai merasa nyaman bekerja, memiliki komitmen dan kesetiaan serta membuat pegawai berusaha lebih keras meningkatkan kinerja pegawai yang kompetitif.

Budaya organisasi publik identik dengan kinerja yang lambat, malasmalasan, tidak tepat waktu dan erat kaitannya dengan Korupsi, Kolusi dan Nepotisme (KKN). Oleh karena itu, kinerja pegawai dalam organisasi publik harus terus diperhatikan sehingga hal penting dalam mewujudkan tata kelola pemerintahan yang baik (good governance). Selain itu untuk mendukung tugas-tugas pemerintahan untuk memberikan pelayanan yang terbaik kepada masyarakat yang berorientasi pada pelayanan publik (public service).

Pada aspek positifnya budaya organisasi akan memberikan sebuah motivasi terhadap karyawannya dalam bekerja. Sehingga karyawan semangat dalam bekerja dan tidak memiliki sifat malas, cenderung dekat antara karyawan dan atasan. Motivasi menyangkut alasan-alasan mengapa orang mencurahkan tenaga, pikiran, serta waktu untuk melakukan suatu pekerjaan. Sangat penting bagi Manajer, Public Relations untuk mengetahui motivasi karyawannya. Informasi tentang motivasi ini merupakan masukan yang penting bagi manajemen untuk mengambil kebijakan yang dapat meningkatkan motivasi karyawan. Diasumsikan motivasi akan berpengaruh pada produktivitas kerja (Kriyantono: 2007, 344). Menurut Devi Santika, Bambang Swasto, dan Heru Susilo dalam penelitiannya yang telah diupload dalam situs linkpdf.com menyatakan bahwa terdapat pengaruh langsung antara variabel budaya organisasi dan variabel motivasi kerja karyawan. Adanya pengaruh langsung antara budaya organisasi dan variabel kinerja karyawan. Begitu pula terdapat pengaruh antara variabel motivasi kerja dan variabel kinerja karyawan. Begitu pula dengan Dinas Pemberdayaan Masyarakat akan memberlakukan karyawannya dengan apa yang telah dibahas tentang budaya organisasi dan motivasi kerja.

Dinas Pemberdayaan Masyarakat merupakan unsur pelaksana urusan pemerintahan bidang pemberdayaan masyarakat yang berkaitan dengan perumusan kebijakan di bidang pemberdayaan masyarakat, pelaksanaan kebijakan bidang pemberdayaan masyarakat, pelaksanaan evaluasi dan pelaporan bidang pemberdayaan masyarakat, pelaksanaan administrasi dinas dengan lingkup tugasnya dan pelaksanaan fungsi lain yang diberikan oleh bupati terkait dengan tugas dan fungsinya.

Pentingnya keberadaan Dinas Pemberdayaan Masyarakat di Kabupaten Majalengka, hal ini memerlukan sumber daya manusia berkualitas yang ada di lingkungan Dinas Pemberdayaaan Masyarakat. Sumber daya manusia yang berkualitas diidentifikasikan yang memiliki kinerja yang handal. Kinerja yang handal bukan merupakan hasil langsung, tetapi melalui proses dan faktor-faktor yang mempengaruhinya.

Pada penelitian ini mengkaji dua faktor yang diduga cukup kuat dalam mempengaruhi aspek kinerja di antaranya budaya organisasi dan motivasi kerja pegawai. Budaya organisasi seringkali 
digambarkan dalam arti yang dimiliki bersama. Menurut Robbins dalam buku yang ditulis Muchlas (2005) Budaya Organisasi adalah sebuah persepsi umum yang dipegang teguh oleh anggota organisasi dan menjadi sebuah sistem yang memiliki kebersamaan penelitian. Dengan demikian budaya organisasi menentukan kepribadian organisasi secara keseluruhan dan memiliki pengaruh yang kuat terhadap perilaku organisasinya, dengan perilaku anggota yang kuat maka anggota bertindak sesuai dengan pemahaman yang mendukung pencapaian tujuan-tujuan penting organisasi.

Motivasi menurut Handoko (1984) merupakan keadaan dalam pribadi seseorang yang mendorong keinginan individu untuk melakukan kegiatan-kegiatan tertentu guna mencapai tujuan. Motivasi yang ada pada seseorang akan mewujudkan suatu perilaku yang diarahkan pada tujuan mencapai sasaran kepuasan. Jadi motivasi bukanlah sesuatu yang diamati tetapi adalah hal-hal yang dapat disimpulkan adanya karena sesuatu yang tampak. Penelitian mengenai pengaruh motivasi terhadap kinerja pegawai dilakukan oleh Luthfi, Susilo dan Riza (2014) bahwa dalam penelitiannya menunjukkan bahwa kinerja para karyawan muncul akibat dari adanya motivasi yang diberikan oleh perusahaan, khususnya dengan adanya bonus, gaji, jaminan-jaminan, serta keamanan, karyawan merasa menjadi lebih aman, nyaman dan terdorong untuk bekerja lebih giat sehingga pekerjaan dapat terselesaikan dengan baik. Penelitian lain Wardani, Mukzan dan Mayowan (2016) bahwa dalam penelitiannya budaya organisasi berpengaruh positif terhadap kinerja karyawan. Penelitian mereplikasi dari kedua penelitian tersebut dengan menambahkan variabel Budaya Organisasi pada penelitian di Dinas Pemberdayaan Masyarakat Kabupaten Majalengka. Berdasarkan uraian di atas, penulis tertarik untuk mengambil judul "Pengaruh Budaya Organisasi dan Motivasi Terhadap Kinerja Pegawai".

\section{METODE PENELITIAN}

Penelitian yang biasa dilakukan oleh peneliti adalah menentukan objek yang akan diteliti sesuai dengan objek yang akan diambil oleh peneliti. Sesuai dengan judul penelitian yang dipilih maka objek penelitiannya difokuskan pada variabel budaya organisasi, motivasi dan kinerja pegawai. Sedangkan subjek pada penelitian ini adalah pegawai yang masih aktif bekerja pada Dinas Pemberdayaan Masyarakat Kabupaten Majalengka yang dimulai dari pimpinan sampai dengan staf pegawai. Jumlah pegawai yang berada di Dinas Pemberdayaan Masyarakat Kabupaten Majalengka sebanyak 32 pegawai yang stratifikasinya terdiri dari golongan II,III dan IV.

Dalam penelitian ini penulis menggunakan metode deskriptif analitis, artinya penelitian yang dilakukan adalah penelitian yang menekankan analisisnya pada data-data numeric (angka) yang diolah. Menurut Sugiyono (2009:21) menyatakan bahwa: "Metode Analisis Deskriptif adalah statistik yang digunakan untuk menganalisis data dengan cara mendeskripsikan atau menggambarkan data yang telah terkumpul sebagaimana adanya tanpa bermaksud membuat kesimpulan yang berlaku untuk umum atau generalisasi".

Tujuan dari penelitian deskriptif ini adalah untuk membuat deskripsi gambaran atau lukisan secara sistematis, faktual dan akurat mengenai fakta-fakta, sifat-sifat serta hubungan antara fenomena yang diselidiki, yaitu Dari pengertiandi atas dapat disimpulkan yang dimaksud dengan metode deskriptif adalah suatu metode yang digunakan dalam penelitian yang mengambarkan suatu peristiwa menurut apa adanya pada saat penelitian dilakukan.

Selain menggunakan metode analisis desktriptif, peneliti juga menggunakan metode analisis inferensial yang digunakan untuk kesimpulan yang lebih luas. Menurut Sugiyono (2009:23) menyatakan bahwa: "Statistik Inferensial adalah statistik yang digunakan untuk menganalisa data sampel, dan hasilnya akan digeneralisasikan (diinferensikan) untuk populasi di mana sampel diambil". Dalam analisis statistik inferensial terdapat dua macam statistik yaitu statistik parametris dan statistik nonparametris. Statistik parametris digunakan untuk menganalisis data interval atau rasio, yang diambil dari populasi yang 
berdistribusi normal. Sedangkan statistik nonparametris digunakan untuk menganalisis data nominal dan ordinal dari populasi yang bebas berdistribusi.

Oleh karena data yang digunakan dalam penelitian ini merupakan data ordinal yaitu persepsi responden tentang variabel budaya organisasi, motivasi dan kinerja pegawai, peneliti menggunakan metode analisis inferensial dengan pendekatan nonparametris untuk mengetahui pengaruh yang diberikan oleh variabel budaya organisasi dan motivasi terhadap kinerja pegawai yang diukur secara parsial dan simultan, maka metode yang digunakannya dengan menggunakan metode analisis jalur (path analysis) secara multivariat

\section{HASIL DAN PEMBAHASAN}

\section{Pengaruh secara parsial dari variabel budaya organisasi dan motivasi kerja terhadap kinerja \\ Analisis jalur untuk pengaruh} langsung maupun tidak langsung dari variabel bebas $(\mathrm{X})$ terhadap variabel terikat (Y), dapat dilukiskan dalam gambar di bawah ini :

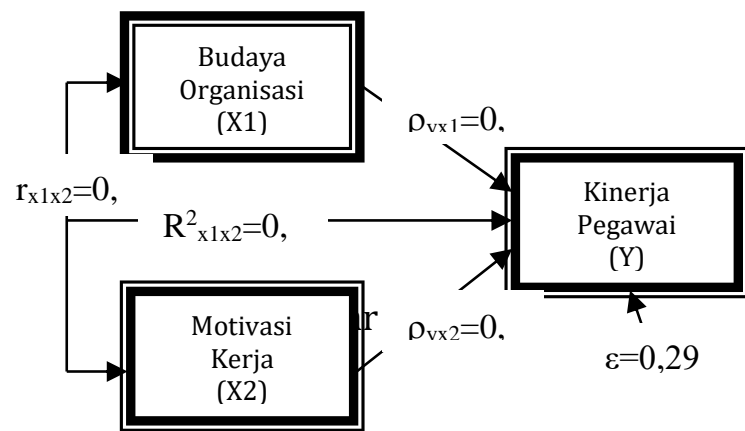

Gambar 1. Diagram jalur Pengaruh X1 dan $\mathrm{X} 2$ terhadap $\mathrm{Y}$

Dari gambar tersebut di atas, maka dapat dijelaskan mengenai besaran koefisien korelasi dan derajat asosiatif atau koefisien jalur dari masing - masing variabel bebas terhadap variabel terikat tersebut, untuk lebih jelasnya dapat dilihat pada tabel di bawah ini :

Tabel 1. Koefisien Jalur Jalur

\begin{tabular}{ll}
\hline Variabel & $\begin{array}{l}\text { Koefisien } \\
\text { Jalur }\end{array}$ \\
\hline Budaya Organisasi (X1) & 0,632 \\
Motivasi Kerja (X2) & 0,246 \\
\hline Sumber : Hasil perhitungan statistik, 2020
\end{tabular}

Dari tabel tersebut dapat diperoleh, bahwa budaya organisasi $\left(\mathrm{X}_{1}\right)$ mempunyai koefisien jalur tertinggi dibandingan dengan variabel motivasi kerja $\left(\mathrm{X}_{2}\right)$. Dari tabel di atas, maka dapat diperoleh persamaan jalur,yaitu :

$\mathrm{Y}=0,632 \mathrm{X}_{1}+0,246 \mathrm{X}_{2}+\varepsilon$

Keterangan :

$$
\begin{aligned}
& \mathrm{Y}=\text { Kinerja Pegawai } \\
& \mathrm{X} 1=\text { Budaya Organisasi } \\
& \mathrm{X} 2=\text { Motivasi kerja }
\end{aligned}
$$

Dari persamaan di atas dapat di artikan bahwa :

1. Adanya hubungan asosiatif antara variabel budaya organisasi $\left(\mathrm{X}_{1}\right)$ dengan kinerja pegawai $(\mathrm{Y})$ yang besarannya sebesar 0,632( $\left.\rho \mathrm{YX}_{1}\right)$

2. Adanya hubungan asosiatif antara variabel motivasi kerja $\left(\mathrm{X}_{2}\right)$, dengan kinerja pegawai $(\mathrm{Y})$ yang besarannya sebesar 0,246 ( $\left.\rho \mathrm{YX}_{2}\right)$

3. Nilai epsilon $(\varepsilon)$ sebesar 0,294 .

2. Pengaruh bersamaan variabel bebas $(X)$ terhadap variabel terikat ( $Y$ )

Adapun besaran pengaruh total (koefisien determinasi) dari variabel bebas budaya organisasi dan motivasi kerja terhadap kinerja pegawai, dinyatakan oleh besaran koefisien determinasi $\left(\mathrm{R}_{\mathbf{Y} 1 \mathrm{X}}\right)^{2}$ yang besarnya adalah sebesar 70,6 \% sedangkan pengaruh variabel lain di luar model adalah sebesar 29,4\%. Untuk lebih jelasnya,dapat dilihat dalam tabel di bawah ini :

\begin{tabular}{|c|c|c|c|c|c|}
\hline \multirow[t]{2}{*}{ Var } & \multirow[t]{2}{*}{$\begin{array}{l}\text { Peng. } \\
\text { Lgsg }\end{array}$} & \multicolumn{2}{|c|}{$\begin{array}{l}\text { Pengaruh } \\
\text { Tidak } \\
\text { Langsung }\end{array}$} & \multirow[t]{2}{*}{$\begin{array}{c}\text { Total } \\
\text { Pengaruh } \\
\text { tidak } \\
\text { langsung }\end{array}$} & \multirow[t]{2}{*}{$\begin{array}{l}\text { Sub. } \\
\text { Total }\end{array}$} \\
\hline & & X1 & $\mathrm{X} 2$ & & \\
\hline $\mathrm{X} 1$ & 0.399 & & 0.123 & 0.123 & 0.522 \\
\hline \multirow[t]{2}{*}{$\mathrm{X} 2$} & 0.060 & 0.123 & & 0.123 & 0.184 \\
\hline & & \multicolumn{3}{|c|}{ Jumlah } & 0.706 \\
\hline
\end{tabular}

Tabel 2. Pengaruh langsung dan tidak langsung $\mathrm{X}_{1}$ dan $\mathrm{X}_{2}$ terhadap variabel $\mathrm{Y}$

Sumber : Hasil perhitungan statistik, 2020

Besaran pengaruh parsial dari variabel budaya organisasi $\left(\mathrm{X}_{1}\right)$ terhadap kinerja pegawai (Y) baik secara langsung maupun tidak langsung sebesar 52,2\%. Besaran pengaruh parsial dari variabel moitvasi kerja $\left(\mathrm{X}_{2}\right)$ terhadap kinerja pegawai $(\mathrm{Y})$ baik secara langsung maupun tidak 
langsung sebesar 18,4\%. Total pengaruh variabel budaya organisasi $\left(\mathrm{X}_{1}\right)$ dan motivasi kerja $\left(\mathrm{X}_{2}\right)$ terhadap kinerja pegawai $(\mathrm{Y})$ sebesar $70,6 \%$.

\section{Pengujian Hipotesis Secara Parsial dan} Bersamaan.

a. Pengaruh Parsial Variabel budaya organisasi (X1), terhadap kinerja pegawai (Y)

Untuk mengetahui pengaruh parsial variabel budaya organisasi (X1) terhadap kinerja pegawai (Y) perlu dilakukan pengujian statistik. Dimana pengujiannya akan menggunakan hipotesis statistik sebagai berikut:

$$
\begin{array}{ll}
\mathrm{H}_{0}:\left(\rho_{\mathrm{x} 1 \mathrm{y}}\right)^{2}=0 & \text { Tidak ada pengaruh } \\
& \text { yang signifikan dari } \\
& \text { Variabel budaya } \\
& \text { organisasi }(\mathrm{X} 1) \\
& \text { terhadap kinerja } \\
& \text { pegawai }(\mathrm{Y}) . \\
& \text { Terdapat pengaruh yang } \\
& \text { signifikan dari Variabel } \\
& \text { budaya organisasi (X1) } \\
\mathrm{H}_{1}:\left(\rho_{\mathrm{x} 1 \mathrm{y}}\right)^{2} \neq & \text { terhadap kinerja } \\
0 & \text { pegawai }(\mathrm{Y}) .
\end{array}
$$

Dengan kriteria uji : tolak $\mathrm{H}_{0}$ jika $\mathrm{t}$ hitung $>\mathrm{t}$ tabel

Tabel 3. Pengujian Parsial Variabel Budaya Organisasi (X1) terhadap Kinerja Pegawai (Y)

\begin{tabular}{cccccl}
\hline Strukt & $\begin{array}{c}\text { Koef. } \\
\text { jalur }\end{array}$ & $\begin{array}{c}\text { t } \\
\text { hitung }\end{array}$ & $\begin{array}{c}\text { t } \\
\text { tabel }\end{array}$ & $\begin{array}{c}\text { p- } \\
\text { value }\end{array}$ & Ksmpln \\
\hline$\rho_{\mathrm{x} 1 \mathrm{y}}$ & 0,632 & 10,365 & 1,960 & 0,000 & $\begin{array}{l}\text { Ho } \\
\text { ditolak, }\end{array}$ \\
\hline
\end{tabular}

Untuk menguji hipotesis tersebut, diperlukan nilai koefisien jalur. Hasil perhitungan menunjukkan nilai $\mathrm{t}$ hitung adalah 10,365. Dengan tingkat signifikansi $(\alpha)=5 \%$ derajat kebebasan (degree of freedom) $=\mathrm{n}-\mathrm{k}-1$ atau 215-3-1 = 211 dan pengujian dilakukan dengan dua sisi (2tiled), diperoleh t tabel sebesar 1,960. Oleh karena nilai $t$ hitung $>t_{\text {tabel }}(10,365>1,960$ ), maka $\mathbf{H}_{0}$ ditolak. Kesimpulannya bahwa Variabel budaya organisasi $\left(X_{1}\right)$ terhadap kinerja pegawai ( $Y$ ) berpengaruh secara signifikan.
b. Pengaruh Parsial Variabel Motivasi Kerja $\left(\mathrm{X}_{2}\right)$, terhadap Kinerja Pegawai (Y)

Untuk mengetahui pengaruh parsial variabel motivasi kerja $\left(\mathrm{X}_{2}\right)$ terhadap kinerja pegawai (Y) perlu dilakukan pengujian statistik. Dimana pengujiannya akan menggunakan hipotesis statistik sebagai berikut :

$$
\begin{aligned}
\mathrm{H}_{0}:\left(\rho_{\mathrm{x} 1 \mathrm{y}}\right)^{2}=0 & \text { Tidak ada pengaruh } \\
& \text { yang signifikan dari } \\
& \text { Variabel motivasi kerja } \\
& \left(\mathrm{X}_{2}\right) \text { terhadap kinerja } \\
& \text { pegawai }(\mathrm{Y}) .
\end{aligned}
$$

$\mathrm{H}_{1}:\left(\rho_{\mathrm{x} 1 \mathrm{y}}\right)^{2} \neq 0 \quad$ Terdapat pengaruh yang signifikan dari Variabel kepemimpinan kepala sekolah $\left(\mathrm{X}_{2}\right)$ terhadap kinerja pegawai ( $\mathrm{Y}$ ). Dengan kriteria uji : tolak $\mathrm{H}_{0}$ jika $\mathrm{t}$ hitung $>\mathrm{t}$ tabel.

Tabel 4. Pengujian Parsial Variabel Motivasi Kerja $\left(\mathrm{X}_{2}\right)$ terhadap Kinerja Pegawai $(\mathrm{Y})$

\begin{tabular}{cccccl}
\hline Strukt & $\begin{array}{c}\text { Koef. } \\
\text { jalur }\end{array}$ & $\begin{array}{c}\text { t } \\
\text { hitung }\end{array}$ & $\begin{array}{c}\text { t } \\
\text { tabel }\end{array}$ & $\begin{array}{c}\text { p- } \\
\text { value }\end{array}$ & Ksmpln \\
\hline$\rho_{\mathrm{x} 1 \mathrm{y}}$ & 0,246 & 4,035 & 1,960 & 0,000 & $\begin{array}{l}\text { Ho } \\
\text { ditolak }\end{array}$ \\
\hline
\end{tabular}

Untuk menguji hipotesis tersebut, diperlukan nilai koefisien jalur. Hasil perhitungan menunjukkan nilai $t$ hitung adalah 4,035. Dengan tingkat signifikansi $(\alpha)$ $=5 \%$ derajat kebebasan (degree of freedom) $=\mathrm{n}-\mathrm{k}-1$ atau $215-3-1=211$ dan pengujian dilakukan dengan dua sisi (2-tiled), di peroleh $t$ tabel sebesar 1,960. Oleh karena nilai $t$ hitung $>t$ tabel $(4,035>1,960)$, maka $\mathbf{H}_{\mathbf{0}}$ ditolak. Kesimpulannya bahwa variabel motivasi kerja $\left(\mathrm{X}_{2}\right)$ terhadap kinerja pegawai $(Y)$ berpengaruh secara signifikan.

c. Pengujian pengaruh secara bersamaan variabel Budaya Organisasi dan Motivasi Kerja terhadap Kinerja Pegawai secara Simultan.

Pengaruh bersamaan variabel-variabel bebas : X1 dan X2 terhadap variabel terikat ( Y ). menggunakan hipotesis statistik sebagai berikut :

$\begin{array}{rlr}\mathrm{H}_{0}: \rho_{\mathrm{yx} 1}=\rho_{\mathrm{yx} 2}=0 & \text { Tidak ada } & \text { pengaruh } \\ & \text { variabel } & \text { budaya } \\ & \text { organisasi } & \text { dan } \\ & \text { Motivasi } & \text { Kerja } \\ & \text { terhadap } & \text { kinerja } \\ & \text { pegawai. } & \end{array}$




$$
\begin{array}{rlr}
\mathrm{H}_{1}: \rho_{\mathrm{yx} 1} \neq \rho_{\mathrm{yx} 2} \neq 0 & \multicolumn{2}{l}{\text { Ada pengaruh variabel }} \\
& \text { budaya organisasi dan } \\
& \text { Motivasi r Kerja } \\
& \text { terhadap rinerja } \\
& \text { pegawai. }
\end{array}
$$

Dengan kriteria uji : tolak $\mathrm{H}_{0}$ jika $\mathrm{F}$ hitung $>\mathrm{F}$ tabel

Untuk menguji hipotesis tersebut,

\begin{tabular}{|c|c|c|c|c|c|c|}
\hline $\begin{array}{l}\text { Mod } \\
\text { el }\end{array}$ & & $\begin{array}{c}\text { Sum of } \\
\text { Squares }\end{array}$ & $\mathrm{df}$ & $\begin{array}{c}\text { Mean } \\
\text { Squar } \\
\text { e }\end{array}$ & $\mathrm{F}$ & Sig. \\
\hline \multirow[t]{3}{*}{1} & $\begin{array}{l}\text { Regressi } \\
\text { on }\end{array}$ & $\begin{array}{r}2258.01 \\
1\end{array}$ & 2 & $\begin{array}{r}1129 . \\
005\end{array}$ & $\begin{array}{r}254 . \\
663\end{array}$ & $\begin{array}{r}.000 \\
\text { (a) }\end{array}$ \\
\hline & Residual & 939.865 & $\begin{array}{r}21 \\
2\end{array}$ & 4.433 & & \\
\hline & Total & $\begin{array}{r}3197.87 \\
5\end{array}$ & $\begin{array}{r}21 \\
4\end{array}$ & & & \\
\hline
\end{tabular}
diperlukan analisis statistik, dimana hasilnya dapat di lihat pada tabel sebagai berikut:

Tabel 5. Pengujian bersama-sama variabel $\mathrm{X}_{1}$ dan $\mathrm{X}_{2}$ terhadap variabel $\mathrm{Y}$

a Predictors: (Constant), X2, X1

b Dependent Variable: $\mathrm{Y}$

Dari tabel di atas, terlihat bahwa F hitung adalah 254,663 dan nilai Sig sebesar 0.000 (a) dengan taraf signifikansi 0,05. Maka dapat disimpulkan bahwa nilai Sig. $<0,05$ sehingga $\mathrm{H}_{0}$ ditolak. Oleh Karena itu secara simultan terdapat pengaruh variabel budaya organisasi dan motivasi kerja terhadap kinerja pegawai

\section{PENUTUP}

Berdasarkan analisis hasil penelitian yang dilakukan sebelumnya, selanjutnya akan dilakukan pembahasan hasil dari analisis atas hubungan motivasi kerja dan budaya organisasi pada kinerja pegawai. Pada penelitian ini yang menjadi obyek adalah pegawai Dinas Pemberdayaan Masyarakat dan Desa Kabupaten Majalengka. Dengan menggunakan analisis regresi linier berganda diperoleh hasil bahwa terdapat hubungan yang siginifikan antara motivasi dan budaya terhadap kinerja pegawai, dapat dijelaskan dibawah ini :

Seseorang dapat dipengaruhi oleh lingkungan dimana dia berada, dengan demikian perubahan yang terjadi baik di dalam individu maupun lingkungan dapat menunjang atau bahkan dapat menghambat kinerja orang yang bersangkutan. Hal-hal tersebut ternyata di dukung oleh hasil yang signifikan dari penelitian yang dilakukan, dimana hasil yang diperoleh menunjukkan bahwa terdapat hubungan yang positif $(+)$ antara budaya organisasi (X1) dan motivasi kerja (X2), dengan kinerja para pegawai (Y). Artinya, semakin tinggi/besar motivasi seseorang untuk bekerja/berprestasi dan semakin tinggi dukungan budaya organisasi yang dirasakan oleh para pegawai maka akan dapat meningkatkan kinerja para pegawainya.

Disamping hasil penelitian tersebut diatas, perlu dijelaskan bahwa kecenderungan untuk berperilaku disiplin banyak dipengaruhi oleh berbagai faktor sebagaimana dikatakan oleh Helmi (1996: 37-38 Dalam Fazria) bahwasanya perilaku kerja dibentuk karena faktor kepribadian dan faktor lingkungan (situasional). Faktor yang penting dalam kepribadian seseorang adalah system nilai yang dianut. System nilai dalam hal ini yang berkaitan langsung dengan disiplin. Nilai-nilai yang menjunjung disiplin yang diajarkan atau ditanamkan orang tua, guru, pimpinan, teman dan masyarakat akan digunakan sebagai kerangka acuan bagi penerapan ditempat kerja. System nilai akan terlihat dalam sikap seseorang. Sikap diharapkan akan tercermin dalam perilaku.

Dalam kehidupan sehari-hari seseorang tidak akan terlepas dari lingkungannya. Kepribadian seseorang akan dibentuk pula oleh lingkungannya dan agar kepribadian tersebut mengarah kepada sikap dan perilaku yang positif tentunya harus didukung oleh suatu norma yang diakui tentang kebenarannya dan dipatuhi sebagai pedoman dalam bertindak. Pendapat diatas sejalan dengan Furnham dan Gunter (dalam Sunarto, 2005), budaya organisasi didefinisikan sebagai keyakinan, sikap dan nilai yang umumnya dimiliki yang timbul dalam suatu organisasi; dikemukakan dengan lebih sederhana, budaya adalah "cara kami melakukan sesuatu di sekitar sini". Budaya organisasi berkaitan dengan konteks perkembangan organisasi, artinya budaya berakar pada sejarah organisasi, diyakini bersama-sama dan tidak mudah dimanipulasi secara langsung. Dalam budaya terkandung apa yang boleh dilakukan atau tidak boleh dilakukan sehingga dapat dikatakan sebagai suatu pedoman yang 
dipakai untuk menjalankan aktivitas organisasi.

Keutamaan dari budaya organisasi merupakan pengendali dan arah dalam membentuk sikap dan perilaku manusia yang melibatkan diri dalam suatu kegiatan organisasi. Sedangkan perilaku itu sendiri sangat ditentukan oleh dorongan / motivasi yang dimiliki dan apa yang mendasari perilakunya. Organisasi yang mempekerjakan individu dengan nilai-nilai organisasi akan menimbulkan kepuasan kerja pegawai, sebaliknya apabila tidak ada kesesuaian antara karakteristik pegawai dengan budaya organisasi akan menimbulkan pegawai kurang termotivasi. Luthans (2006), menyatakan budaya organisasi mempunyai sejumlah karakteristik penting. Beberapa diantaranya adalah:

Aturan perilaku yang diamati, Ketika anggota organisasi berinteraksi satu sama lain, mereka menggunakan bahasa, istilah, dan ritual umum yang berkaitan dengan rasa hormat dan cara berperilaku.

Norma, adalah standar perilaku, mencakup pedoman mengenai seberapa banyak pekerjaan yang dilakukan, yang dalam banyak perusahaan menjadi "jangan melakukan terlalu banyak; jangan terlalu sedikit." Nilai dominan, Organisasi mendukung dan berharap peserta membagikan nilai-nilai utama. Contohnya adalah kualitas produk tinggi, sedikit absen, dan efisiensi tinggi.

Filosofi, Terdapat kebijakan yang membentuk kepercayaan organisasi mengenai bagaimana pegawai dan atau pelanggan diperlakukan. Aturan, Terdapat pedoman ketat berkaitan dengan pencapaian perusahaan. Pendatang baru harus mempelajari teknik dan prosedur yang ada agar diterima sebagai anggota kelompok yang berkembang.

Iklim Organisasi, Merupakan keseluruhan "perasaan" yang disampaikan dengan pengaturan baru yang bersifat fisik, cara peserta berinteraksi, dan cara anggota organisasi berhubungan dengan pelanggan dan individu dari luar. Kalau enam kriteria itu terpenuhi dan dapat diterima maka pegawai akan bekerja dengan maksimal tapi kalau sebaliknya jika ke enam kriteria diatas atau beberapa kriteria tidak diterima pegawai maka akan berpengaruh pada kinerja pegawai.

Kinerja pegawai akan maksimal tatkala kebutuhan-kebutuhan dalam mendukung pekerjaan tersebut terpenuhi seperti yang dijelaskan oleh Adanya keterkaitan hubungan antara budaya dengan kinerja organisasi yang dapat dijelaskan dalam model diagnosis budaya organisasi bahwa semakin baik kualitas faktor-faktor yang terdapat dalam budaya organisasi makin baik kinerja organisasi tersebut (Moelyono Djokosantoso, 2003). Berdasarkan hasil perhitungan analisis verifikatif faktor budaya organisasi secara empiris merupakan faktor yang dinilai sangat dominan dalam mempengaruhi kinerja pegawai dengan koefisien korelasi sebesar 0,632 , hal ini menunjukkan adanya hubungan yang kuat.

Motivasi sangatlah penting dalam mempengaruhi pegawai, karena bagaimanapun seseorang akan berbuat/melakukan sesuatu berdasarkan apa yang ia inginkan, sebagaimana dalam bukunya '"manajemen sumber daya manusia". Martoyo (2000: 164 Dalam Fazria) menyatakan bahwa motivasi merupakan suatu dorongan yang menjadi pangkal seseorang dalam melakukan sesuatu atau bekerja. Keterangan diatas dapat dibuktikan dengan hasil penelitian ini yang menunjukan hubungan motivasi kerja dengan kinerja mendapatkan hasil terdapat hubungan antara motivasi kerja dengan kinerja Berdasarkan perhitungan korelasi antara motivasi kerja terhadap kinerja, diperoleh koefisien korelasi sebesar 0.234 , hal ini menunjukan adanya hubungan yang masih positif meskipun rendah kontribusinya bila dibandingkan dengan budaya organisasi.

Berdasarkan hasil penelitian yang dilaksanakan di Dinas Pemberdayaan Masyarakat dan Desa dengan menggunakan subjek sebanyak 48 orang tentang hubungan motivasi kerja dengan kinerja mendapatkan hasil bahwa terdapat hubungan antara motivasi kerja dengan kinerja Berdasarkan perhitungan korelasi antara motivasi kerja terhadap kinerka, diperoleh koefisien korelasi sebesar 0.631, hal ini menunjukan adanya hubungan yang kuat. Sedangkan 
dalam mengetahui hubungan antara budaya organisasi dengan kinerja, berdasarkan perhitungan korelasi antara motivasi kerja terhadap budaya organisasi, diperoleh koefisien korelasi sebesar 0.648, hal ini menunjukanbahwa terdapat hubungan dengan tingkat korelasi yang sangat kuat. Berdasarkan keterangan diatas maka dapat disimpulkan bahwa budaya organisasi lebih mempengaruhi kinerja di Dinas Pemberdayaan Masyarakat dan Desa dibandingkan dengan motivasi yang nilainya lebih rendah dari budaya organisasi.

\section{DAFTAR PUSTAKA}

Abdullah dan Arisanti Herlin. 2010. Pengaruh Budaya Organisasi, Komitmen Organisasi dan Akuntabilitas Publik terhadap Kinerja Organisasi. Jurnal Ekonomi dan Bisnis. Vol.9, No. 2, Agustus, hal.122. Bengkulu: Universitas Bengkulu.

Abdul Wahab, Solichin. 2012. Analisis Kebijaksanaan dari Formulasi ke Implementasi Kebijaksanaan Negara. Jakarta : Bumi Aksara.

Achmad Sobirin. 2007. Budaya Organisasi (Pengertian, Makna dan Aplikasinya dalam

Kehidupan Organisasi).Yogyakarta: UPP. STIM

Agustini, Fauziah. 2007. Manajemen Sumber Daya Manusia Lanjutan. Medan: Madenatera

Agustino, Leo. 2006. Dasar-Dasar Kebijakan Publik. Bandung: Alfabeta

Almasdi dan Jusuf Suit. 2012. Aspek Sikap Mental Dalam Manajemen Sumber Daya Manusia. Jakarta: Syiar Media.

Ancok,D. 2012. Psikologi Kepemimpinan dan Inovasi. Jakarta: Erlangga.

Anderson, James E. 1979. Public Policy Making. New York : Holt, Reinhart and Winston

Baker, Chris. 2006. Cultural Studies Teori \& Praktik. Yogyakarta : Kreasi Wacana.

Brynard, Petrus A. 2005. Policy Implementation : Lessons for services Delivery (paper of 27th
AAPM Annual Rountable Conference in Zambia).

Casida, Jesus and Genevieve Pinto-Zipp. 2007. Leadership-Organizational Culture Relationship in Nursing Units of Acute Care Hospitals. Nursing Economics. Vol.26, No.1, pp. 7-15.

Cho. 2006.

Diagnosing.

Organizational Cultures : Validating a Model and Method. Journal.

Christensen. 2012. An exploration of industry, culture and Revenue. Dibuka pada tanggal 5 Juli 2012. Dibuka melalui: www. Findarticle.com.

Davis, Keith dan Newstorm. 1996. Perilaku Dalam Organisasi. Edisi Tujuh. Jakarta: Erlangga.

Denison, D. R. 2006.Corporate Culture and Organizational Effectiveness.United State of America.

Dunn, William N. 2003. Analisis Kebijakan Publik. Yogyakarta: Gadjah Mada University Press.

Dwijowijoto, Riant Nugroho. 2004. Kebijakan Publik Formulasi, Implementasi dan Evaluasi. Jakarta : PT Elex Media Komputindo Kelompok Gramedia.

Edward III, George C. 1980. Implementing Public Policy. Washington DC : Congressional Quarterly Press.

Fahmi, Irham. 2010. Manajemen Kinerja Teori dan Aplikasi. Bandung : CV. Alfabeta

Gibson, et al. 1996. Organisasi (Perilaku, Struktur dan Proses), Edisi kedelapan. Jakarta : Binaarupa Aksara

Gomes, Faustino Cardoso. 2002. Manajemen Sumber Daya Manusia. Yogyakarta: Penerbit Andi Offset.

Greenberg, J., \& Robert, A.B.1995. Behavior in Organizatuional: Understanding and Managing The Human Side of Work. $5^{\text {th }}$ Edition. New Jersy: Prentice-Hall International.Inc.

Hardiansyah. 2011. Kualitas Pelayanan Publik. Konsep, Dimensi, Indikator dan Implementasinya. Yogyakarta : Gava Media.

Hofstede, G. 1997. Cultures and Organizations: Software of the Mind. 
Edisi Revisi. New York : Mc GrawHill

Husein, Umar. 2010 Evaluasi Kinerja Perusahaan. Jakarta : Gramedia Pustaka Utama.

Islamy, M. Irfan. 2000. Kebijakan Publik. Jakarta : Karunika

Kartasasmita, Ginanjar. 1997. Administrasi Pembangunan : Perkembangan Pemikiran dan Praktiknya di Indonesia. Jakarta : LP3ES

Kasmir. 2005.Etika Customer Service. Jakarta : PT Raja Grafindo Persada.

Keban, Yeremias. T. 1994.Enam Dimensi Strategis Administrasi Publik Konsep, Teori dan Isu. Jakarta : Elex Media Komputindo

Kinicki, Angelo and Robert Kreitner. 2008. Organizational Behaviour: Key Concepts, Skills\& Best Practices. New York : Mc Graw-Hill Companies.Inc.

Kotlerdan Keller, 2012. Marketing Management Edisi 14. Global Edition Pearson. Prentice Hall.

Kotter, J.P. dan J.L. Heskett. 1992. Corporate Culture and Performance. New York : Free Press.

Kusdi, 2011. Budaya Organisasi Teori, Penelitian dan Praktik. Jakarta : Salemba Empat

Kusumanegara, Solahuddin. 2010. Model dan Aktor dalam Proses Kebijakan Publik. Yoyakarta : Gava Media.

L. Daft, Richard. 2010. Era Baru Manajemen. Jakarta : Salemba.

Luthans, Fred. 2002. Organizational Behavior, Ninth Edition. Singapore: Mc Graw Hill International Editions.

Mardiasmo. 2004. Akuntansi Sektor Publik. dalam www.bppk.kemenkeu.go.id

Mangkunegara, Anwar Prabu. 2003. Perencanaan dan Pengembangan Sumber Daya Manusia. Bandung : Refika Aditama.

Mangkunegara, A.A. Anwar Prabu. 2009. Evaluasi Kinerja Sumber Daya Manusia. Bandung : Refika Aditama.

Mangkunegara, A.A. Anwar Prabu. 2010. Manajemen Sumber Daya Manusia. Bandung: PT. Remaja Rosdakarya.
Mangkuprawira, Sjafri. 2007. Manajemen Mutu Sumber Daya Manusia. Bogor: Ghalia Indonesia.

Marquis BL, Huston CJ. 2010. The Leadership Rules and Management Functions in Nursing : Theory and Application. 3rd edition. Philadelphia :Lippincolt.

Moeheriono. 2009. Pengukuran Kinerja Berbasis Kompetensi. Jakarta : Ghalia Indonesia

Moenir. 2006. Manajemen Pelayanan Umum di Indonesia. Jakarta: Bumi Aksara.

Mowat, Joanne. 2002. Corporate Culture. htt p://www.herridgegroup.com/pdfs /corp cultures.pdf

Muhajir, Darwin. 1999. Analisis Kebijakan Publik. Yogyakarta : Hanindita

Mustopadidjaja. 2007. Manajemen Proses Kebijakan Publik, Formulasi, Implementasi dan Evaluasi Kinerja. Jakarta : Perum Percetakan Negara RI

Ndraha, Talidziduhu. 2003. Kybenology (Ilmu Pemerintahan Baru) Jilid 1 dan 2. Jakarta :Rineka Cipta.

Pasolong, Harbani. 2011.Teori Administrasi Publik. Bandung :Alfabeta.

2010. Kepemimpinan Birokrasi. Bandung : CV. Alfabeta

Pressman dan Wildavsky. 1978. Implimentation as to carry out, accomplish, fullfil, produce, complete. Barkley and Los Angeles: University of California Press.

Price, Andrea C. 2003, A Culture Assessment of Manufacturing Company. Research .

Poerwadaminto. 2003. Kamus Umum Bahasa Indonesia. Jakarta : Balai Pustaka

Purwanto, Erwan Agus dan Dyah Ratih Sulistyastuti. 2012. Implementasi Kebijakan Publik : Konsep dan Aplikasinya di Indonesia. Yogyakarta :Gava Media.

Ratminto. 2005. Manajemen Pelayanan. Yogyakarta: Pustaka Pelajar.

Ripley, Randall B. and Greace A. Franklin. 1986. Policy Implementation and Bureaucracy. Chicago : The Dorsey Press. 
Robbins. P. Stephen. 2005. Organization Behavior. USA. Pearson PrenticeHall.Pearson International.11th Edition.

Robbins, P.S. 2010. Perilaku organisasi. Edisi Bahasa Indonesia, edisi 10.Jakarta : PT. Indeks.

Sedarmayanti. 2010. Manajemen Sumber Daya Manusia, Reformasi Birokrasi dan Manajemen Pegawai Negri Sipil. Bandung: PT. Refika Aditama.

Siagian, Sondang. 1996. Filsafat Administrasi. Jakarta : CV. Haji Masagung

Sinambela, L.P. 2010. Reformasi Pelayanan Publik; Teori, Kebijakan dan Implementasi, cetakan kelima. Jakarta: PT. Bumi Aksara.

Sinambela, Lijan Poltak, dkk. 2012. Kinerja Pegawai Teori Pengukuran dan Implikasi. Yogyakarta : Graha Ilmu.

Sobirin, Achmad. 2007.Budaya Organisasi : Pengertian, Makna dan Aplikasinya dalam Kehidupan Organisasi. Yogyakarta :UPP STIM YKPN.

Subarsono. 2005. Analisa Kebijakan Publik. Yogyakarta : Pustaka Pelajar.

Suharto, Edi. 2012. Analisis Kebijakan Publik. Bandung : Alfabeta.

Sulistiyani. 2003. Manajemen Sumber Daya Manusia. Jakarta : CV. Ghalia Indonesia.

Sunggono, Bambang. 1994. Hukum dan Kebijaksanaan Publik. Jakarta : Sinar Grafika.

Suradinata, Ermaya. 1993. Manajemen Pemerintahan dan Otonomi Daerah. Bandung: CV. Ramadhan

Susanto, A.B. 1997. Budaya Perusahaan. Jakarta : PT Elex Media Komputindo.

Sutrisno, Edy. 2010. Budaya Organisasi. Jakarta : Kencana.

Sutrisno, dkk.2006.Teknologi
Penyediaan Air Bersih. Jakarta : Rineka Cipta.

Sutrisno, Edy. 2010. Manajemen Sumber Daya Manusia. Jakarta : PT. Prenada Media.
Swastika. 2005. Pengaruh Pelayanan Prima (Service Excellence) terhadap Kepuasan Pelanggan. Jurnal Ekonomi.

Tachjan. 2006. Implementasi Kebijakan Publik. Bandung : AIPI BandungPuslit KP2W Lemlit UNPAD

Tangkilisan, Hessel Nogi S. 2003. Kebijakan Publik Yang Membumi. Yogyakarta : YPAP

Tappen. 1995. Nursing Leadership And Management: Concepts \& Practice. Philadelphia : F.A. Davis Company.

Tjiptono, Fandy. 2012. Service Management Mewujudkan Layanan Prima. Yogyakarta: CV Andi Offset.

Wibisono, Dermawan. 2006. Manajemen Kinerja. Jakarta : Erlangga.

Wibowo. 2010. Manajemen Kinerja. Jakarta : Rajawali Pers

Widodo, Joko.2010. Analisis Kebijakan Publik. Malang: Bayumedia.

Winarno, Budi. 2005. Teoridan Proses Kebijakan Publik. Yogyakarta : Media Pressindo (Anggota IKAPI).

Winarno, Budi. 2012. Kebijakan Publik Teori, Proses dan Studi Kasus. Yogyakarta : CAPS

Wirawan. 2007. Budaya dan Iklim Organisasi. Jakarta : Salemba Empat.

Zeithaml, valarie A., A. Parasuraman \& Leonard L. Berry. 1990. Deliverring Quality Service. New York : The Free Press

Zwan. 2006. Assessing Organisational culture in a Private Hospital in the western cape. University of Western Cape. Dibuka pada tanggal 2 April 2015.Diambil melalui: www.pdf.com. 


\section{BIOGRAFI PENULIS}

\begin{tabular}{|l|l||}
\hline & Vina Monica Triany merupakan Mahasiswa Pascasarjana pada Program Studi Ilmu \\
& Administrasi, di bawah bimbingan Dr. H. Lalan Soeherlan S., M.Si dan Dr. H. Aceng \\
& Jarkasih, M.Si dengan penelitian yang berjudul Pengaruh Budaya Organisasi dan \\
& Motivasi Kerja terhadap Kinerja Pegawai yang dilakukan pada Dinas Pemberdayaan \\
& Masyarakat Kabupaten Majalengka. \\
& Email: aqueena.sugiarto@gmail.com \\
\hline
\end{tabular}

